\title{
Euthanasia in Holland: an ethical critique of the new law
}

\author{
H Jochemsen Lindeboom Institute, the Netherlands
}

\begin{abstract}
In the Netherlands the government's proposal for the legal regulation of euthanasia, assisted suicide and the termination of a patient's life without request has been approved by Parliament. The defence of this proposal is to a large extent based on a specific interpretation of data about the practice of euthanasia in that country, published in 1991 (the Remmelink Report). This paper discusses both the interpretation of the data and the new law. On the basis of that and other data, the author concludes that many cases of euthanasia, assisted suicide and termination of a patient's life without request remain unnotified and therefore unreviewed by the legal authorities. It is argued that the new law will not guarantee an improvement to this situation. In short, the new law will not protect effectively the lives of patients, and must, therefore, be open to ethical and legal objection.
\end{abstract}

\section{Introduction}

On November 30, 1993, the First Chamber of the Dutch Parliament accepted the Cabinet's proposal for the legal regulation of euthanasia. Many in other countries see Dutch attempts to regulate euthanasia as an experiment (1). Therefore, it is worthwhile to consider the claim of the Dutch government that this law will effectively protect the lives of patients while respecting the autonomy of those patients who want euthanasia. This requires first of all a presentation and interpretation of the situation in Dutch medical practice with respect to medical decisions concerning the end of life. Then, the new law will be discussed in the light of that practice and of the debate about the proposal in Parliament. The paper will conclude with an assessment of the government's claim.

\section{Investigation}

The discussion in the Netherlands about some form of legalisation of euthanasia has been going on for

\section{Key words}

Allowing to die; euthanasia; voluntary/involuntary withholding of treatment; bills, laws and cases. several years now. In this discussion euthanasia is defined as the intentional termination of the life of a patient at his/her request by a physician. (Internationally the request of the patient does not form part of the definition.) Two legislative $\vec{N}$ proposals had been presented, but neither had been 0

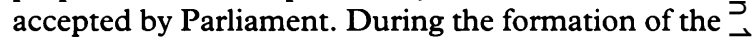
present government ${ }^{\star}$ it was agreed that the practice $\square$ of life-terminating actions in health care would be investigated before a further proposal for legislation was presented to Parliament. This investigation has been performed by Van der Maas and collaborators, commissioned by a state committee chaired by $\vec{\ominus}$ Professor J Remmelink, Attorney-General at the Supreme Court. The results are presented in

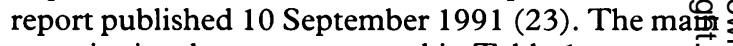
quantitative data are presented in Table 1.

The committee concluded from these figures that $\frac{2}{\Phi}$ in the Netherlands there is a careful practice of $\overrightarrow{\vec{F}}$ euthanasia (4). It was pointed out that while $9,000 \frac{\text { 을 }}{3}$ people asked for euthanasia, only 2,300 got it. Some concern was expressed about the 1,000 cases of unrequested termination of life. But on the basis of the answers of the respondent physicians, it was $\underset{\overline{0}}{\overrightarrow{0}}$ concluded that the life-terminating actions in these $\sigma$ cases should be interpreted and, in most cases, condoned as 'help in dying' (5).

\section{Careful practice?}

I do not consider that those results justify optimism with respect to the practice of euthanasia in the Netherlands for the following reasons:

1. The finding that 9,000 requests for euthanasia $N$ led to 'only' 2,300 cases of euthanasia (6) can be interpreted in different ways. On the one hand it shows indeed that in the Netherlands physicians are not terminating patients' lives just on demand, if $\frac{\overrightarrow{\mathbb{D}}}{2}$ anyone ever believed that. But this also means that $\stackrel{\mathcal{P}}{+}$ the request of the patient is not in practice the basis $\square$

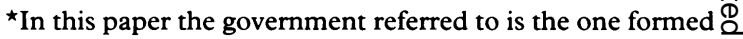
in 1989. In May 1994 there were elections and a new government was formed.
} 


\section{Deaths from all causes in the Netherlands}

$$
\begin{gathered}
129,000(100 \%) \\
9,000(7 \cdot 0) \\
2,300(1 \cdot 8) \\
400(0 \cdot 3) \\
1,000(0 \cdot 8) \\
22,500 \\
14,400(11 \cdot 3) \\
6,750(5 \cdot 2) \\
1,350(1 \cdot 0) \\
\\
5,800(4 \cdot 5) \\
22,500(17 \cdot 5) \\
\\
14,625(11 \cdot 4) \\
4,275(3 \cdot 3) \\
3,600(2 \cdot 8)
\end{gathered}
$$$$
\text { Life terminated without a specific request }
$$$$
\text { - partly with the purpose of shortening life }(30 \%)
$$$$
\text { - with the explicit purpose of shortening life }(6 \%)
$$

- at the request of the patient
- without the request of the patient

- taking into account the probability that life would be shortened $(65 \%)$

- partly with the purpose of shortening life $(14 \%)$

Table 1. The main quantitative data from the report of the committee Onderzoek medische praktijk inzake euthanasie (Investigation of medical practice with regard to euthanasia). (All figures cover one year [1990]. In brackets is the percentage of the total number of deaths.)

on which physicians decide to perform euthanasia, but rather they base such decisions on the condition of the patient. This is supported by the finding that 1,000 people actually had their lives terminated without an explicit request (7). The request seems to function as a circumstance that makes it legally, and probably morally, easier for the physician to perform euthanasia, but it is basically the condition of the patient, not the request, which is the real ground for euthanasia in many cases. Respect for patient autonomy had been put forward as the main argument in favour of the acceptance of euthanasia, but it provides an inadequate explanation for the practice of euthanasia in the Netherlands.

This being so, it is to be feared that the acceptance of terminating the life of a patient in a certain condition at his request, will lead to the acceptance of terminating the life of a patient in a similar condition, without request. In other words, the practice of euthanasia in the Netherlands seems to entail an inherent slippery slope.

2. The conclusion of the Remmelink Committee that one should regard those 1,000 cases as 'help in dying', is not convincing. For if they had been, the physicians who reported them would have categorised them under the heading of intensification of pain and symptom treatment with the explicit purpose of shortening life. But they evidently distinguished those actions from the intensification of pain treatment. Furthermore, although about a quarter of the patients were competent to a certain extent (8), the physicians had not discussed with them the possibility of shortening life. The numbers (from the interviews with physicians) also show that about 20 per cent of those 1,000 patients had a life expectancy longer than one to four weeks, and that an additional 8 per cent had a life expectancy of more than one month (9).

3. It is unclear how the intensification of pain and symptom treatment and the withholding of lifesaving medical treatment, partly with the purpose or with the explicit purpose of shortening the life of the patient, should be interpreted. In about 30 per cent of these cases the attending physician indicated that a decision of this kind shortened life by more than one week.

In the course of the discussion in the Netherlands it has been agreed that the following three categories of actions should not be considered as euthanasia (10): a. stopping or not beginning a treatment at the request of the patient, $b$. withholding a treatment that is medically useless, c. pain and symptom treatment with the possible side-effect of shortening life.

Intensification of pain and symptom treatment and forgoing medical treatment can be good medical practice, even when this may involve a shortening of life. The important question with respect to these actions ( $b$ and $c$ ) is whether the physician chose proportional pain and symptom treatment and whether or not he initiated proportional lifesustaining treatment. If so, the physician's actions should not be considered euthanasia, either voluntary or non-voluntary. For euthanasia is not just defined by the (concomitant) intention to shorten life, which is in itself morally reproachable, nor by a certain shortening of life as a side-effect, but by the factual intentional shortening of life, either by commission or by omission.

However, the questions in the inquiry focused on the intention of the physician, not on the 
proportionality of his medical treatment. Therefore, it is unclear whether, and if so in how many cases of these two groups of patients, the physician aimed to hasten the patient's death either by providing disproportional pain treatment or by withholding proportional medical treatment. The data of the lifeexpectancy of those patients at least suggest that in a considerable percentage this was indeed the case (11). Furthermore, it should be noted that in 20-30 per cent of cases in which pain treatment was intensified and/or life-supporting treatment was withheld, with the explicit purpose or partly with the purpose of shortening life, the physician had not consulted a fully competent patient (12). Here again we see that in practice the autonomy principle is not the decisive factor in the decisions of physicians to perform an action (or an omission) aimed at shortening life.

4. The results also indicate that after performing euthanasia 65-75 per cent of the physicians falsely and unlawfully certify death by natural causes (13), even though the risk of prosecution if the requirements for careful medical practice have been observed, is negligible (14). This shows both that the physicians are very reluctant to have their lifeterminating actions supervised by the legal authorities and that in the large majority of cases it is unknown whether the requirements for careful medical practice are observed. This conclusion is supported by recent research by Van der Wal et al (15). This has provided more detailed information about the way physicians notify cases of euthanasia. Some of the main results can be summarized thus: a. Important reasons for failing to notify are that the physician wants to avoid the administrative fuss involved and does not want to bother the family with the investigation by the legal authorities (16). b. The cases that are reported represent a sample of all cases in which the requirements that the courts consider important have been met, whereas this is less so for the unnotified cases (15). c. The reports of cases that are notified describe the patient's situation in terms that are thought to satisfy the legal authorities and which differ in some respects from the description given in the anonymous inquiry (17).

The reported findings indicate that the legal authorities cannot adequately control the practice of euthanasia. This would in the first place require the notification of every case of euthanasia. In fact, the number of cases that were reported has increased in these last two years (18). It is likely that the present legal regulation of euthanasia will further increase the notification rate of cases in which the requirements are stated to have been met. However, in the light of the above research it is to be feared that it will not prove possible for any regulation either to provide an accurate picture, or to enable the legal authorities to control euthanasia effectively (19).

\section{The new law}

The new law containing a regulation of euthanasia (20) reflects the optimism of the Remmelink Committee and seeks to maintain the government's responsibility for the effective protection of human life, while respecting the wishes of those who want euthanasia. The Dutch Supreme Court has tried to reconcile these two aims by ruling that the physician who has committed euthanasia can, in cases of an objectively established 'conflict of duties' appeal to a defence of 'necessity'. Thus, although euthanasia and assisted suicide remain unlawful (penal code, art 293, 294), the courts have decided that a doctor can in certain circumstances successfully invoke the defence of necessity (21). The government decided not to alter this situation but rather to approve it and to give the reporting procedure that has existed since November 1, 1990 a statutory basis. So the new law is in fact not so much a regulation of euthanasia, as a regulation of a reporting procedure of euthanasia. According to this procedure a doctor who has terminated a patient's life informs the local medical examiner, who inspects the body externally and takes from the attending physician a statement which contains the relevant data (the patient's history, request, possible alternatives, consultation with a second physician, intervention, etc). This report, together with an evaluation by the locat medical examiner, is checked by the public prosecutor who then must consider whether the termination of the patient's life was contrary to the penal code as interpreted by the courts.

\section{The government's position: a critique}

1. The Cabinet seeks to justify its position by referring to the acceptance of euthanasia in medical ethics and in Dutch jurisprudence, and of lifeterminating actions by the Dutch medical profession. However, seen in an international context euthanasia is not ethically accepted. On the contrary, the predominant view is that it is unethical (22). Moreover, the Cabinet's opinion on the acceptability of euthanasia in the Netherlands is largely based, as argued above, on the Remmelink Committee's questionable interpretation of the data generated by the survey of Van der Maas et al.

2. It is true that the Dutch penal code provides the defence of 'necessity' (art 40). However, by definition this defence of necessity can be described in general terms only. In each particular case it is up to the court to determine whether or not the defence is available. Indeed, the courts have decided that for a physician to have such a defence to a charge of euthanasia he must be in an 'emergency' due to a 'conflict of duties' and comply with 'responsible' medical practice. But whether such an 'emergency' exists is considered to be a matter for medical judgement (23). And what the courts consider 'responsible' practice appears to be heavily 
influenced, if not decided, by the medical profession. The requirements for 'careful' or 'responsible' medical practice function as a description of a situation in which the physician's appeal to 'necessity' will be accepted (24). The Minister of Justice has denied that this use of the defence of necessity defeats its purpose (25). But it cannot be denied that this defence in fact is being used to overrule the unambiguous article prohibiting euthanasia (26). Moreover, the physician who reports the life-terminating action is the self-same physician who performed it; is he likely to disclose any incriminating circumstances?

3. The data gathered on behalf of the Remmelink Committee show that the Cabinet's classification of life-terminating actions that must be reported is not as precise as it should be. The reportable actions are euthanasia, assisted suicide and life-terminating actions without request. But the intensification of pain treatment and the withholding of treatment with the explicit aim of shortening life do not come within the definition of these actions, nor under the definition of those actions that are not to be considered euthanasia (see point 3 above). It remained unclear, therefore, whether in the Cabinet's opinion these actions had to be reported. Only in the Memorandum of Reply (27) do the responsible ministers make it clear that the intensification of pain and symptom treatment with the intent of shortening life should not be considered normal medical practice and are therefore reportable in the same way as euthanasia.

This statement, while formally consistent with the Cabinet's proposal as a whole, raises new problems. First, to the number of patients whose life was intentionally terminated, either with or without a specific request, at least 1,350 and probably more, should be added (see Table 1). In about 60 per cent of the cases in which pain treatment was given in such doses that life was almost certainly shortened there had been no request by the patient (28). So the situation is quantitatively more serious than has been suggested up to now (see point 2 , page 2 ). The same could be said for the cases in which treatment was withheld with the aim of shortening life (29), which would make the situation even more serious, but the responsible ministers do not comment on these latter actions.

Second, in the light of the findings of Van der Maas et al, and Van der Wal et al about the frequency and manner in which physicians report their life-terminating actions (see point 4 , page 3 ), it is surely unlikely that doctors will in the future report their actions adequately, particularly if the patient has not been consulted. It must be expected, therefore, that many if not most life-terminating actions, even if they involve the intentional shortening of life, will remain invisible to justice.

4. In one respect the Cabinet's opinion differs from the position of the Remmelink Committee. As indicated above the committee interpreted the 1,000 reported cases of the termination of life without a request as cases of 'help in dying' and therefore as part of normal medical practice. The Cabinet disagrees. It stresses the need to control these life-terminating actions and concludes that the intentional termination of life without the patient's request must be reported following the same procedure as euthanasia. Indeed the Cabinet takes this view because, as the unrequested killing of a patient by the physician is not (yet) accepted by the courts, every such case should be brought before a court.

During the debate about the Cabinet's proposal, both in the Second Chamber (April 1992 and February 1993) and in the First Chamber (May and November 1993), this apparent equation of requested with unrequested life-terminating actions, was the most criticised aspect of the proposal and was attacked by all parties, including those which favour the legalisation of euthanasia on request. The Government responded to this criticism by saying that in the design of the reporting form and in the rubric of the requirements for careful medical practice, life-terminating actions on request will be distinguished from those without request (30). However, they rejected the idea of two different reporting forms or procedures to avoid the suggestion that notifications of euthanasia (on request) could be handled by a standard procedure (31).

Although the Cabinet stresses that the prohibition of any life-terminating action is maintained in the penal code, it explicitly leaves open the possibility that under specific circumstances the courts will accept the necessity defence in cases of intentional termination of life without request.

It should be noticed in this context that euthanasia is accepted by the courts largely because of advocacy by the medical profession and that the main organisation representing this profession, the KNMG (Royal Dutch Medical Association), has now also accepted the termination of the life of incompetent patients in specific circumstances (32). It is not unlikely, therefore, that the courts will accept it as well, probably again by applying the necessity defence. Is the Government not leaving decisions about the termination of the lives of vulnerable groups of patients (for example, the mentally handicapped, the demented) far too much in the hands of the medical profession and of the courts?

\section{Conclusion}

5. The data published by the Remmelink Committee and by others indicate that the majority of cases in which doctors intentionally shorten patients' lives, either by act or omission remain unnotified, unchecked and invisible to justice. It is evident, therefore, that a practice of terminating patients' lives is continuing which is not adequately controlled by the legal authorities and that the new law will simply confirm and perhaps even encourage 
this practice. The claim of the government that this new regulation will enable the legal authorities effectively to protect human life, is surely unsubstantiated. And although we have certainly not reached a situation of 'euthanasia on demand', any practice of euthanasia, whatever one may think of it morally, which is not open to legal scrutiny must be considered inconsistent with the rule of law. This largely unregulated practice has arisen in no small measure as a result of the dearth of prosecutions by the authorities over the last two decades. The Dutch experience shows that once the termination of patients' lives is practised and that practice wins official toleration or approval, the practice develops a dynamic of its own that resists effective control. In sum, the new legislation protects life no more, and very probably less, effectively than did the old.

\section{Acknowledgement}

The author is deeply indebted to Dr J Keown, for many valuable remarks on an earlier version of this paper.

Henk fochemsen, PhD, has been the Director of the Professor $\operatorname{Dr} G A$ Lindeboom Institute, a centre for medical ethics, since 1987. Address: Postbox 224, 6710 $B E$ Ede, the Netherlands.

\section{References and notes}

(1) See for example: Pence G E. Do not go slowly into that dark night: mercy killing in Holland. American journal of medicine 1988; 84: 139-141; Nowell-Smith $P$. Euthanasia and the doctors - a rejection of the BMA's report. Fournal of medical ethics 1989; 15: 124-128; Carton $\mathrm{R} \mathrm{W}$. The road to euthanasia. fournal of the American Medical Association 1990; 263, 16: 2221; Singer P A, Siegler M. Euthanasia - a critique. New England journal of medicine 1990; 322, 26: 1881-1883; Keown J. The law and practice of euthanasia in the Netherlands. The law quarterly review 1992; 108: 51-78; Dying well? A colloquiy on euthanasia and assisted suicide. Hastings Center report 1992; 22, 2: 6-59; Lutterotti $M$ von. Grenzen ärztlicher behandlungspflicht und passive sterbehilfe. Zeitschrift für medizinische ethik 1993; 39, 1: 3-14.

(2) Commissie onderzoek medische praktijk inzake euthanasie. Rapport medische beslissingen rond het levenseinde (Report on euthanasia and other medical decisions concerning the end of life). Den Haag: SDU-uitgeverij 1991. This is the report of the Remmelink Committee. See also reference (3).

(3) Van der Maas P J, Van Delden J J M, Pijnenborg L. Euthanasia and other medical decisions concerning the end of life. Health policy 1992; 22, 1/2: 1-262; also published as hardback edition by Elsevier Science Publishers, Amsterdam 1992. For a short summary of this report see: Van der Maas P J, et al. Lancet 1991; 338: 669-674. An extensive discussion about the situation in the Netherlands can be found in: Wachter M A M de. Euthanasia in the Netherlands. Hastings Center report 1992; 22, 2: 23-30, and: Have H A M J ten, Welie JVM. Euthanasia: normal medical practice? Hastings Center report 1992; 22, 2: 34-38.

(4) See for example Beleid beschouwd, No 5784. Den Haag: Rijksvoorlichtingsdienst 1991: Sept 30. (A collection of photocopies of articles from newspapers, published by the state's public relations service).

(5) See reference (2): chapter 5.3.

(6) See reference (3): Van der Maas et al, table 5.2; chapter 5.2 and chapter 17.3.

(7) See reference (3): Van der Maas et al, chapter 6.9 and chapter 17.4 .

(8) See reference (3): Van der Maas et al, table 6.4.

(9) See reference (3): Van der Maas et al, table 6.10.

(10) Leenen H J J. Dying with dignity: developments in the field of euthanasia in the Netherlands. Medical law $1989 ; 8: 520$.

(11) See reference (3): Van der Maas et al, table 7.3.

(12) See reference (3): Van der Maas et al, tables 7.7 and 8.12 .

(13) See reference (3): Van der Maas et al, table 5.14.

(14) Van der Wal G. Euthanasie uit strafrecht, maar sterven niet bureaucratiseren. Nederlands juristenblad 1993; 13: 444-449. A table (p 446) presenting the numbers of cases of euthanasia that were reported and that were prosecuted from 1981 to 1992 shows that in 1988 and 1989 only three cases were prosecuted (the investigation of Van der Maas et al (3), refers to 1990); see also reference (18).

(15) Van der Wal G, Eijk J Th $M$, Leenen $H$ J J, Spreeuwenberg C. Medisch contact 1991;46, 7; 211-215: 1992; 47, 2: 43-47: 1992;47, 31/300 905-909: 1992; 47, 36: 1023-1028.

(16) See reference (15): 1992; 47, 2: 45

(17) See reference (15): 1992; 47, 36: 1023-1028.

(18) The Annual Report of the Public Prosecutor, 1993 Sept 1, records that in 1991590 cases of euthanasia or assisted suicide were reported and in 19921,318 cases; in 1991 a prosecution procedure was started in one case and in 1992 in four cases.

(19) See reference (14): Van der Wal favours the decriminalisation of euthanasia (on request), arguing that only this would make euthanasia controllable by the medical profession itself and would limit it to cases that in the profession's opinion would be acceptable. Apart from the problem that then one profession would have the power to terminate the lives of people without judicial control, why is it thought that physicians would be any the readier to report cases of euthanasia in which the guidelines were not followed?

(20) Standpunt van het Kabinet inzake medische beslissingen rond het levenseinde (Position of the Cabinet with respect to 'Euthanasia and other medical decisions concerning the end of life'). Ministerie van Justitie, Den Haag, 1991 Nov 8. At the presentation of this proposal the Undersecretary of State for Health Care spoke of 'a civilised practice of euthanasia'. See $\omega$ also Meinders P R. De kalmerende toets van een $\underset{<}{\sigma}$ beschaafde praktijk (The calming test of a civilised $c$ practice). Reformatorisch dagblad 1991; Nov 9: 3. In fact the new law (bill No 22572) regulating euthanasia does not set out the grounds for euthanasia but sets out the $\tau$ reporting procedure to be followed when euthanasia has been performed. It amends the law on the disposal of the dead (article 10). This article provides the legal basis for a form used by physicians to certify natural death. The amended law provides that both the form to $\widetilde{\gamma}$ certify natural death and the form to notify all cases of 
euthanasia, assisted suicide and a life-terminating action without request will be set out in a later enactment ('Algemene Maatregel van Bestuur', AMvB; this $\mathrm{AMvB}$ has been published as Besluit van 1993 Dec 17: Stb 688, in Staatsblad 1993 Dec 28.

(21) These circumstances are essentially formulated in the so called requirements for careful medical practice when performing euthanasia. These are, in short: free, well-considered request; unacceptable suffering; consultation by the physician with a colleague. See reference (10): Leenen.

(22) At its 39th meeting in Madrid, in October 1987, the World Medical Association unanimously accepted the following declaration: 'Euthanasia, that is the act of deliberately ending the life of a patient, even at the patient's own request or at the request of close relatives, is unethical. This does not prevent the physician from respecting the desire of a patient to allow the natural process of death to follow its course in the terminal phase of sickness'. See: Coppes M J. Verslag 39e bijeenkomst van de World Medical Association van 4 t/m 1987 Oct 8 te Madrid. Vita humana 1987; 14, 4: 156-157. Also in 1987, meeting in Berlin, the Standing Committee of Doctors of the EC adopted a declaration about palliative care and euthanasia. Stressing very much the need to stop futile medical treatment and to provide palliative care in a terminal stage, it condemned the intentional termination of the life of patients. (A propos de l'euthanasie; document CP $86 / 76 \mathrm{~F}$; the original is in French). Only the KNMG voted against this declaration. In 1976 the Parliamentary Assembly of the Council of Europe accepted a recommendation on the rights of the sick and the dying ( $\operatorname{Rec} 779,1976)$. One of the considerations of the declaration runs as follows: 'Considering that the doctor must make every effort to alleviate suffering, and that he has no right, even in cases which appear to him to be desperate, intentionally to hasten the natural course of death'. Yet, it must be recognised that, at least in some countries there appears to be an increasing level of acceptance of voluntary euthanasia. The Appleton International Conference. Fournal of medical ethics 1992; 18 (suppl) part I: 8 (note 15).

(23) In its landmark decision of November 27, 1984, the Supreme Court made clear that in the case of an appeal to a defence of necessity, a court should investigate whether according to 'responsible medical opinion', measured by the 'prevailing standards of medical ethics' a situation of necessity existed. (For a more extensive discussion see reference (1): Keown. In their reply to questions asked by members of the First Chamber, the responsible ministers also explicitly state that to determine the legitimacy of a physician's appeal to necessity, an understanding is necessary of the emergency (noodsituatie) in which the patient finds himself. This, the ministers say, is a medical judgement. Memorandum of Reply (MoR), 1993 Jun 11:43. (The MoR is the written response of the Cabinet to questions raised in Parliament.)

(24) The ambiguity, if not contradiction, in this law comes out very clearly in a recent Government statement (in the so called Further Memorandum of Reply, 1993 Sept 7). On the one hand it is stated that 'the proposed reporting procedure does not contain material criteria with respect to the acceptability of life-terminating actions in whatever form ...' (p 5), whereas elsewhere it is said that punishment should not be inflicted when 'the requirements for careful medical practice as mentioned in the reporting procedure that is used since Nov 1, 1990, are met' (p 8).

(25) Handelingen van de Tweede Kamer (Minutes of the Second Chamber) TK 44, 1993 Feb 2: 3318, 3320; see also reference (23): MoR: 8, 12, 28.

(26) Concern over the broadening of the use of the necessity defence has been heightened by two recent prosecutions of doctors for assisting psychologically disturbed persons to commit suicide. In both cases the physicians were acquitted by the courts; for the first case see: Court of Appeal, The Hague, 1993 May 25: 'Hulp bij zelfdoding' (Assisted suicide). Tijdschrift voor gezondheidsrecht 1993; 17, 6: 360-368; for the second case see: Court of Appeal Leeuwarden, 1993 Sept 30: 'Hulp bij zelfdoding' (Assisted suicide) Tijdschrift voor gezondheidsrecht 1993; 17, 8: 500-505. The Leeuwarden case concerned a woman who did not have a psychiatric illness, but who wanted to die because of very sad, personal experiences, including the death of her two sons, one of whom committed suicide. The Hague case concerned a woman who for a number of years had been treated unsuccessfully for depression and who had attempted to commit suicide. In both cases the courts accepted the defence of necessity, using the formulation of the Supreme Court in its decision in 1984 (see reference (23)). In both cases the Public Prosecutor has appealed to the Supreme Court. In its decision of 21 June 1994 the Supreme Court revised the courts' decision regarding the Leeuwarden case in the sense that stricter requirements were formulated for assisted suicide by physicians in case of psychic suffering, yet essentially accepting the physician's appeal to the defence of necessity in such cases.

(27) See reference (23): MoR: 15

(28) See reference (3): Van der Maas et al: table 7.7.

(29) See reference (3): Van der Maas et al, chapter 8.3.1 and 18.4. The data from the interviews with physicians do not indicate whether in cases when pain treatment was intensified or treatments were withheld or withdrawn, the extent to which the patient was consulted differed between the situations 'taking into account the probability', 'partly with the aim' and 'with the explicit aim' of shortening life. Results from two other parts of the research by Van der Maas et al, $v i z$ the prospective survey and the survey of death certificates, indicate that for each of these groups the patients were not consulted in about 45-60 per cent of cases, except for the group of prescribing or administering drugs with the explicit aim to hasten death of which about 20 per cent of the patients were not consulted; see reference (3), table 13: table F3, and also table 15.1.

(30) See reference (23): MoR: 5.

(31) Further MoR, 1993 Sept 7: 3.

(32) Since 1990 the KNMG has published four discussion papers defending the ethical acceptability in special circumstances of life-terminating actions with severely handicapped newborn babies (Utrecht, 1990), persistent comatose patients (Utrecht, 1991), severely demented patients (Utrecht, 1993) and psychiatric patients (Utrecht, 1993). 